The BMJ

Cite this as: BMJ 2021;375:n3083 http://dx.doi.org/10.1136/bmj.n3083 Published: 14 December 2021

\title{
Covid-19: GPs are told to postpone routine care to focus on vaccine boosters in response to omicron
}

\section{Gareth lacobucci}

The UK government has announced a further acceleration to the covid booster vaccine programme in response to the rapid spread of the omicron variant and has promised that every UK adult will be able to book a booster by the end of 2021.

To free up capacity in the health service general practices are being asked to postpone routine appointments and focus on delivering vaccinations, alongside urgent appointments for conditions such as cancer, over the next two weeks.

England's health and social care secretary, Sajid Javid, told the House of Commons on 13 December that the UK now had 4713 confirmed cases of omicron and that the current number of daily covid infections was estimated to be as high as $200000 .{ }^{1}$ He said that in England there were 10 people in hospital with the new variant and that the government had reported the first UK death from omicron.

The government has also raised the UK alert level to four, its second highest level, in response to the spread of omicron.

"I acknowledge that our national mission comes with some difficult trade-offs," Javid said. "We are redeploying NHS staff away from non-urgent services. These are steps that no health secretary would wish to take unless they were absolutely necessary, but I am convinced that if we do not prioritise the booster now the health consequences will be far more grave in the months that lie ahead."

The ramping up of the booster programme ${ }^{2}$ comes a fortnight after the government first expanded eligibility and pledged to offer boosters to everyone over 18 by the end of January. ${ }^{3}$ This prompted GP leaders to call for extra staff and capacity to deliver the ambitious target, and NHS England subsequently announced that parts of the Quality and Outcomes Framework (QOF) would be suspended until April to free up GPs' time. ${ }^{4}$

In response to the surge in omicron cases the NHS in England will now open up online bookings for boosters to all over 18 s from 15 December.

To facilitate this, every local area has been asked to substantially increase the number of appointments they have for vaccinations, extend opening hours at vaccine centres, and have centres open seven days a week. The NHS will also open more pop-up sites in locations such as trucks and buses, parks, shopping centres, sports stadiums, and leisure centres.

Martin Marshall, chair of the Royal College of General Practitioners, said, "Practices understand the need to prioritise the booster programme, and it is important that we are provided with guidance by NHS England to help us to deprioritise non-essential work.
Amid the chronic shortage of family doctors and other team members in general practice, the profession will also need to be supplemented by additional staff, perhaps redeployed from elsewhere in the NHS, retirees and medical students, and volunteers."

Marshall added, "People will not stop being sick or needing GP care for other illnesses and conditions. This has been a balancing act general practice has been treading throughout the pandemic-and GPs and our teams will continue to strive to ensure patients who need our care are able to get it in a safe and appropriate way."

Matthew Taylor, chief executive of the NHS Confederation, said it was important for the government to send a "crystal clear message" to the public that its decision to focus more resources on vaccination "could lead to disruption elsewhere in the service.”

He said, "Health leaders recognise the government has made a strategic assessment of risk, but after everything their teams have been through over the last two years they do not want to see the NHS, including primary care, unfairly criticised for the unintended consequences of this policy."

Chaand Nagpaul, BMA council chair, said that although vaccine boosters were an "essential weapon" against omicron, the government should also initiate additional protections over and above the vaccination programme, given that many people will not receive their booster straight away. "This requires robust infection control measures in the community, especially where people mix in indoor settings," he said.

\section{High demand for lateral flow tests}

To help slow the spread of omicron the government also advised that from 14 December people who are fully vaccinated and who have been identified as a contact of someone with covid-19, whether the omicron variant or not, should take a lateral flow test every day for seven days.

But the announcement was followed by numerous reports on 13 December of people being unable to order home lateral flow tests because of lack of availability. Duncan Robertson, a data analyst working on covid-19 modelling and analysis at Loughborough University, tweeted, “Considering a large part of the government's strategy depends on access to lateral flow tests (10 days of daily testing if [you are] a contact), this is a big problem."5

The UK Health Security Agency said that there was no shortage of lateral flow tests and that the government had enough stock to meet demand, but it added that it sometimes stopped taking orders 
online for brief periods when there demand was too high. A spokesperson said, "Everyone who needs a lateral flow test can collect test kits either at their local pharmacy, some community sites, and some schools and colleges.

"Due to exceptionally high demand, ordering lateral flow tests on gov.uk has been temporarily suspended to fulfil existing orders.”

1 Covid-19 update-in the House of Commons at 3:32 pm on 13th December 2021. They Work for You. 13 Dec 2021. https://www.theyworkforyou.com/debates/?id=2021-12-

13a.792.0\&s=Sajid+Javid\#g796.0.

2 Mahase E. Covid-19: Omicron and the need for boosters. BMJ2021;375:n3079.

3 lacobucci G. Covid-19: GPs need extra staff and capacity to deliver accelerated booster programme, say leaders. BMJ2021;375:n2982. doi: 10.1136/bmj.n2982 pmid: 34857586

4 NHS England. Letter: JCVI advice in response to the emergence of the B.1.1.529 (omicron) variant: next steps for deployment. 3 Dec 2021. https://www.england.nhs.uk/coronavirus/wp-content/uploads/sites/52/2021/12/C1468-jvci-advice-in-response-to-the-emergence-of-the-b.1.1.529-omicronvariant-next-steps-for-deployment.pdf.

5 Robertson D. Twitter. 13 Dec 2021. https://twitter.com/Dr_D_Robertson/status/1470333436426653699?s=20. 